\title{
ANALYTICAL HIERARCHY PROCESS FOR IDENTIFICATION OF SUITABLE WATER HARVESTING SITE IN GEOSPATIAL ENVIRONMENT
}

\author{
Shashikumar B.N. ${ }^{*}$, Vaibhav Garg², Bhaskar R. Nikam² \\ ${ }^{1}$ Agricultre and Soil Department, Indian Institute of Remote Sensing, ISRO, Dehradun, India - shashiwatershed@gmail.com \\ ${ }^{2}$ Water Resources Department, Indian Institute of Remote Sensing, ISRO, Dehradun, India - (vaibhav, bhaskarnikam)@iirs.gov.in
}

\section{Commission V, SS: Natural Resources Management}

KEY WORDS: Water harvesting structures, analytical hierarchy process, remote sensing, geographic information system, land use land cover, check dam.

\begin{abstract}
:
Water is the prime requirement for agriculture, domestic uses and industrial production. In India the per capita available of water is decreasing at a higher rate due to impact of climate change and ever-increasing population. Rainwater harvesting is the technique which is being used in effective storing of surface runoff. There are various types of water harvesting structures namely check dam, farm pond, percolation tank, etc. However, identification of potential site for the construction of the particular water harvesting structure is bit difficult as it depends upon numerous parameters such as soil type, slope, water availability, land use and land cover of the site and the surrounding, etc. The guidelines such as Food and Agriculture Organization; Integrated Mission for Sustainable Development are available for selecting suitable site for water harvesting structures. As the site suitability analysis involves multiple parameters for decision making, in the present study, the selection of suitable site for check dam is made through analytical hierarchy process (AHP) in geospatial domain for Hatni watershed, Madhya Pradesh, India. As location for check dam construction is influenced by soil texture, slope of the terrain, land use land cover, stream order and water availability; these parameters were derived from remote sensing data and analysed. The slope and stream network layers were generated from the digital elevation model (DEM). Further, the influence of soil and water availability in identifying the suitable sites was studied through soil texture and curve number. Different parameters influence the site suitability analysis, therefore, in the present study, IMSD guidelines were used to assign weights to each parameter under consideration. The layers were assigned weights by AHP technique based on pairwise comparison. The layers were reclassified according to the weights, then overlay analysis has been done to get the final site suitability map. As remote sensing provides the synoptic coverage of the earth, it has been further utilised to study the impact of water harvesting structure on its surrounding. The land use land cover map of before and after the construction of water harvesting structure was analysed for change in vegetation condition. It was observed that the vegetative cover has increased after implementation of the water conservation measures. It may be concluded that the geospatial technology has immense potential in site suitability studies for water harvesting structures.
\end{abstract}

\section{INTRODUCTION}

Water is one of the most important element for survival of life on the earth. It is the dynamic natural resource, which needs proper management for the sustainable utilisation ( Naseef and Thomas, 2016). Water is a prime requirement for agriculture, domestic uses and industrial production. For biomass production and socioeconomic development in dry areas the components of precipitation resolved into soil moisture and ground water are prerequisites (Ramakrishnan et al., 2008). Rainwater harvesting is the technique used in effective storing of surface runoff. In general water harvesting is a system that collects the rainwater from where it falls and around its periphery without letting it go as runoff. In the watershed scale rainwater harvesting is generally done through construction of suitable structures to arrest the flowing surface runoff. Additional advantages of water harvesting structures are that it acts as the barrier to soil erosion and prevent flooding in the downstream. Check dams, Farm ponds, Percolation ponds, subsurface dykes, Bunds etc. are some widely used water harvesting structures. However, selecting suitable site for water harvesting structure construction depends on various local parameters such as topography, soil, availability of water and proximity to potential users. It is to be noted that the selection of site for water harvesting, considering various aspects involved, with minimum investment and maximum output is difficult manually. Integrated Mission for Sustainable Development
(IMSD, 1995) and Food and Agriculture Organisation (FAO, 1977) guidelines are summarised and used in selecting the suitable site for water harvesting structures (IMSD, 1995).

On the other hand, the remote sensing provides synoptic coverage of the earth surface at regular interval and its data can easily be analysed and visualised in geographical information system (GIS) domain. It can provide the situation of the land (land use land cover), terrain topography (elevation, slope, drainage network), and further these parameter can be analysed for runoff calculation. Therefore, the appropriate site selection for water harvesting structures is possible from geospatial techniques to increase water availability (both in surface water and ground water storage) so that it can effectively be used for irrigation, domestic and other purposes (Sharma \& Thakur, 2007). In this study suitable site for check dam construction in Hatni watershed, Madhya Pradesh, India is identified using geospatial techniques. As discussed earlier, the selection of site depends upon various parameters, in this study, the soil texture, stream order, slope and curve number (as proxy to water availability) were used. Each of these parameters will have different influence of the selection of the potential site for water harvesting structure and its performance. The parameters and their influence was decided based on the IMSD guidelines (IMSD, 1995) Several methods are used for site selection for water harvesting structures, Analytical Hierarchy Process (AHP) is among the best approaches to handle multiple and heterogeneous factors which. AHP is based on a hierarchic

${ }^{*}$ Corresponding author 
structure to represent the importance and relationships of factors in multi-criteria decision situation (Saaty, 1980). Pairwise comparison is used to simplify the process. It has become a new trend that using multi-criteria decision making and mainly AHP method with GIS in site suitability analysis for water harvesting structures (Akinci et al., 2013; Krois and Schulte, 2014). For identification of sites, in which GIS technique were employed to processing of spatial data and AHP methods were used to assign weights for different factors and suitable scores were subjectively assigned to each factor. As the remote sensing provides the earth coverage at regular interval, the technology can further be utilized to study impact of water harvesting. In the present study, the two different time period (before and after the water conservation measures) LULC were analysed to study the change in vegetative surface.

\section{STUDY AREA AND DATA USED}

The study area selected is Hatni watershed which is in Jhabua district of Madhya Pradesh, India. The watershed is bound between latitudes $22^{0} 32^{\prime} 30^{\prime \prime} \mathrm{N}-22^{0} 38^{\prime} 30^{\prime \prime} \mathrm{N}$ and longitudes $74^{0} 16^{\prime} 30^{\prime \prime} \mathrm{E}-74^{0} 24^{\prime} 30^{\prime \prime} \mathrm{E}$. The geographical area occupied by Hatni watershed is 8505.67 ha. The area included extremely hilly area comprising number of parallel ranges rising abruptly from the level ground. The area is undulating with a number of small hillocks rising 10 to $30 \mathrm{~m}$ above the surrounding area. This area is selected since harvesting structure are best suited because of varying slope and soil. The annual average rainfall observed in the Hatni watershed as around $880 \mathrm{~mm}$ (Talati et al. 2005).

\subsection{Data Used}

The imagery of Landsat 4-5 TM and Landsat-8 OLI with spatial resolution of $30 \mathrm{~m}$ were used to prepare land use land cover and Normalised Difference Vegetation Index (NDVI) maps of the watershed. ASTER Global DEM with spatial resolution of $30 \mathrm{~m}$ is used for watershed boundary updation, drainage network and slope generation. The remote sensing and DEM data has been downloaded from USGS website (https://earthexplorer.usgs.gov/). The soil texture information were retrieved from National Bureau of Soil Survey and Land Use Planning (NBSS\&LUP) soil database available at 1:250,000 scale.

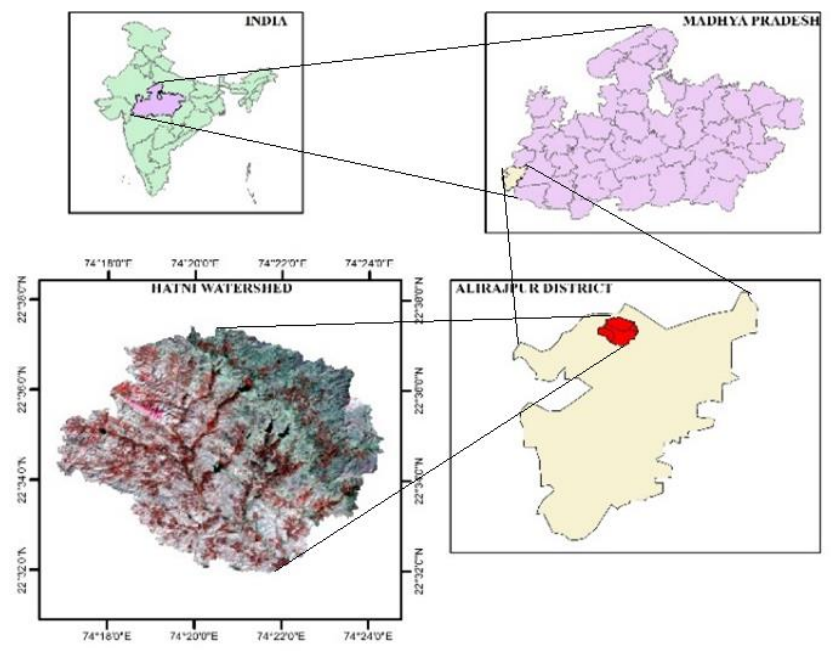

Figure 1 Location map of the study area: Hatni Watershed

\section{METHODOLOGY}

The main objective of this study is to identify suitable site for construction of check dam using AHP in geospatial environment. As the suitable site selection for check dam depends upon various parameters, the study started with preparation of different layers needed to make decision such as soil texture, slope, stream order and curve number map of the study area. The generated layers were assigned weightage using AHP technique. Finally, the weighted overlay analysis has been carried out in GIS domain to generate final site suitability map. In the present study, the parameters and their influence was based on the IMSD guidelines. The factors used in the AHP process are discussed below.

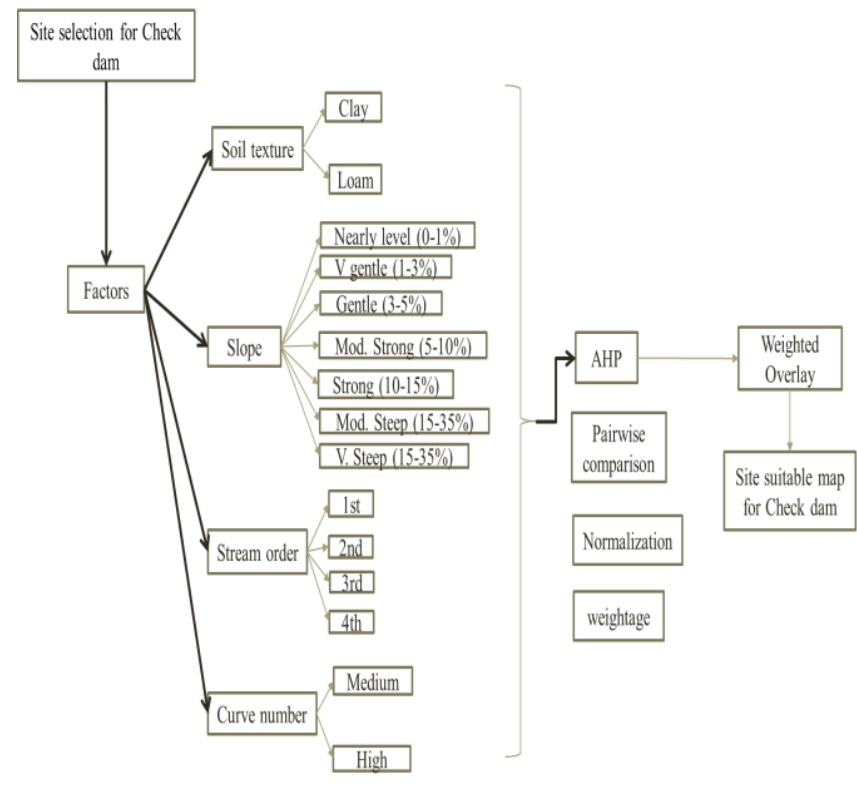

Figure 2 Overall methodology flowchart

\subsection{Preparation of Thematic Layers}

\subsubsection{Slope}

Slope is the degree of steepness or gradient of line which describes the steepness and direction of line. It was used for calculating steepness of slope. In identifying the suitable sites for water harvesting structure like Check dam slope is the one of the most important factors which describes terrain steepness and surface runoff potential. Slope (in percentage) map is generated from ASTER DEM using "Surface" function of ArcGIS under Spatial Analyst Tool. The generated slope map was then reclassified into number of classes from nearly level to very steep sloping as suggested by the IMSD guidelines as shown in Figure 3. Most of the area in the study region falls moderately sloping class.

\subsubsection{Stream order}

The relative size of stream is represented as stream order. The smallest tributaries is referred to as first order stream while the largest tributaries are given highest order. The ASTER DEM is used to generate the stream network and steam order maps through DEM hydro-processing using Spatial Analyst Tools of ArcGIS. The study area has $4^{\text {th }}$ order stream as the highest order stream as shown in Figure 4, hence it can be said that Hatni watershed is $4^{\text {th }}$ order watershed. As per the IMDS guidelines the suitable sites for Check dam must be selected up to second and third order streams. 


\subsubsection{Soil texture}

Soil is the most important factor since it holds the water at surface. The site selection for check dams is most preferable in clay soils because it has lowest infiltration and percolation rates. The study area is comprised of mostly clay and loamy type of soil texture as shown in Figure 5. Based on their runoff potential, the soil texture map was reclassified in hydrologic soil groups (HSG) as suggest by (SCS, 1972). The HGS map was used to generate the curve number map.

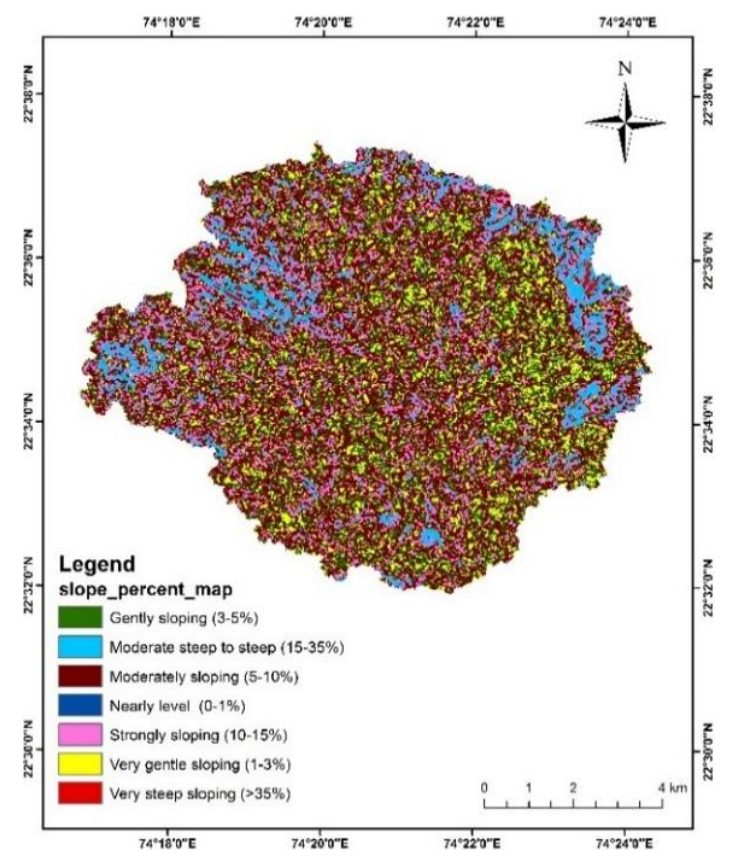

Figure 3 Slope percent map

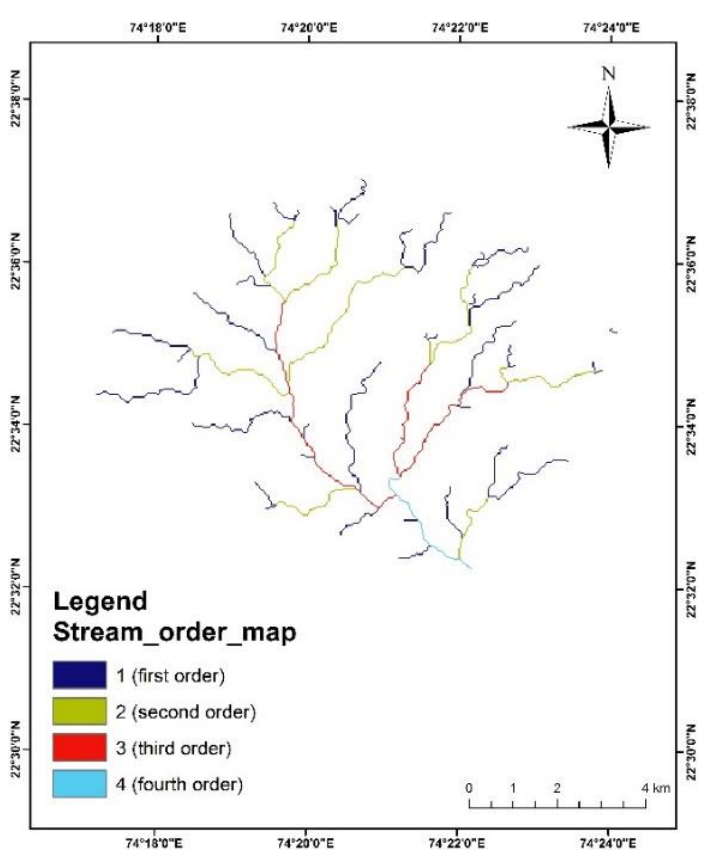

Figure 4 Stream order map of Hatni Sub-watershed

\subsubsection{Curve number}

The curve number method is used for determining the appropriate amount of runoff from a rainfall in a particular area. In the present analysis, the most commonly used Natural Resource Conservation Services - Curve Number method (formerly known as Soil Conversation Services- Curve Number method) was realised in GIS environment for estimation of curve number as a proxy to runoff potential of the watershed. The curve number map was generated by crossing LULC and HSG maps. The site selection for Check dams is more favourable in medium values of curve number. As higher runoff means more water which may results in failure of the structure or in such situation (high runoff) harvesting is not much required.

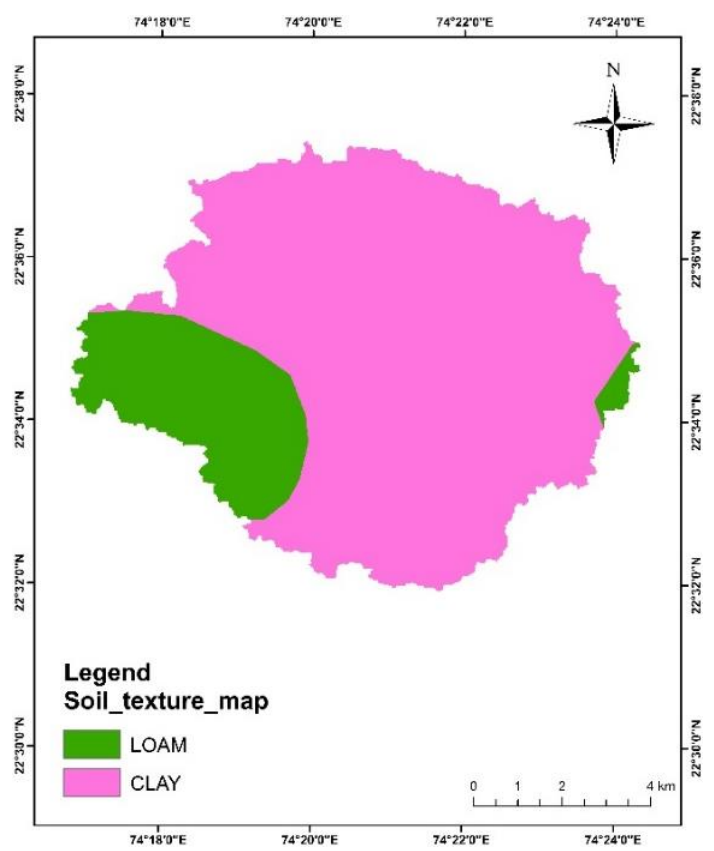

Figure 5 Soil texture map (Source: NBBSLUP)

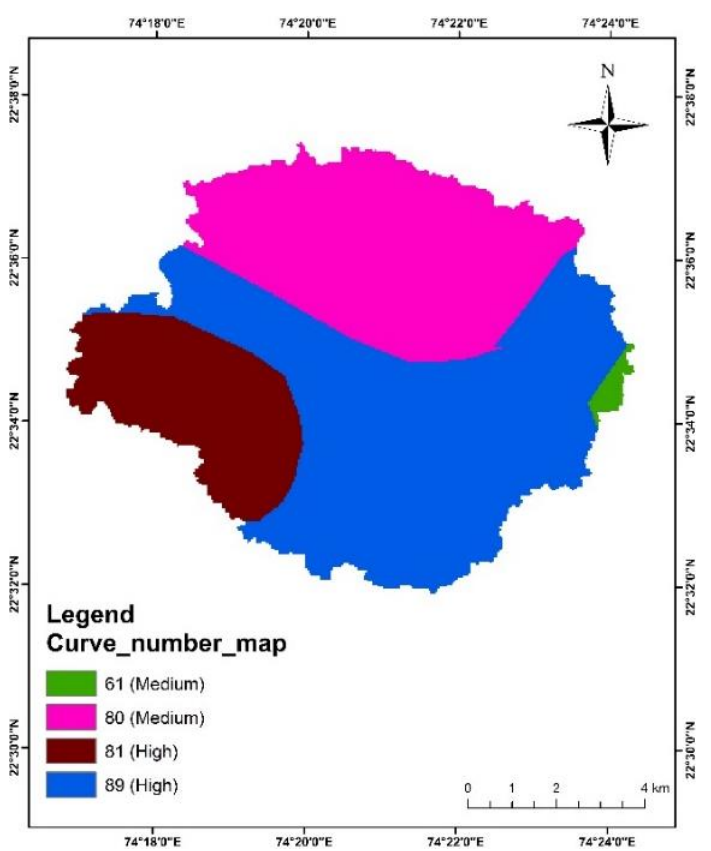

Figure 6 Curve number map 


\subsection{Determination of Weight by AHP}

Complex problems which involve multiple criteria function can be solved by assigning weights to the factors for decision making. Chances of misperception is more in a situation when logical and well-structured decision making procedure is not carried. The present study adapted the widely used AHP method for multi criteria decision making, which was introduced by Saaty (1980). AHP is widely accepted statistical and is a very popular means to calculate weightage for factors with the help of a preference matrix where all identified relevant criteria are compared against each other with reproducible preference factors. The factors selected will be considered as relevant for decision making process by AHP and all factors are compared with each other in a pair-wise comparison matrix and this is the process measure to express the relative preference among the factors (Sener et al., 2010). Therefore, numerical values expressing a judgment of the relative importance of one factor against another have to be assigned to each factor. Preferences to the parameters under consideration are given using preference descriptor proposed by Saaty (1980) as given in Table 1.

\begin{tabular}{|c|l|}
\hline Intensity & \multicolumn{1}{|c|}{ Importance } \\
\hline 1 & Equal importance \\
\hline 2 & Equal to moderate importance \\
\hline 3 & Moderate importance \\
\hline 4 & Moderate to strong importance \\
\hline 5 & Strong importance \\
\hline 6 & Strong to very strong importance \\
\hline 7 & Very strong importance \\
\hline 8 & Very to extremely strong importance \\
\hline 9 & Extreme importance \\
\hline Reciprocals & Values for Inverse Comparison \\
\hline
\end{tabular}

Table 1 The Saaty's scale of importance

The suitable site of check dam was selected after weighted overlay analysis of four layers pertaining to soil texture, terrain slope, stream order and curve number. The relative weightage of each layer and its sub-class was derived using AHP technique. Suitable sites for construction of check dam were categorised in three categories (e.g. less suitable, suitable and highly suitable). The accuracy of selected sites was checked against the sites of constructed structures in the watershed.

\subsection{Assessment of Impact of Water Harvesting on Vegetative Cover of the Surrounding}

To study the impact water harvesting measurers on the watershed, the LULC changes in two different time periods - before (1989) and after (2017) the water conservation measures was analysed. The LULC maps were generated using the Landsat 4-5 TM data of December, 1989 and Landsat 8 OLI of December, 2017. Both the images were taken for the same season to avoid the seasonality effect. The change in vegetative surface was then analysed to study the impact of water harvesting measures implemented in the watershed.

\section{RESULTS AND DISCUSSION}

The main aim of this study was to locate suitable site for check dam for water conservation in Hatni watershed. As the site suitability analysis involve consideration of many parameters influencing the performance of the structure under consideration, in the present study, AHP approach has been adapted for decision making. For the present analysis, the parameters such as soil texture, slope, and stream order and curve number were considered based on IMSD recommendations as shown in Table 2 .

\begin{tabular}{|l|l|l|l|l|l|}
\hline Structure & $\begin{array}{l}\text { Slope } \\
(\%)\end{array}$ & $\begin{array}{l}\text { Porosity and } \\
\text { permeability }\end{array}$ & $\begin{array}{l}\text { Runoff } \\
\text { potential }\end{array}$ & $\begin{array}{l}\text { Stream } \\
\text { order }\end{array}$ & $\begin{array}{l}\text { Catchment } \\
\text { area, ha }\end{array}$ \\
\hline $\begin{array}{l}\text { Check } \\
\text { dams }\end{array}$ & $<15$ & Low & $\begin{array}{l}\text { Medium/ } \\
\text { high }\end{array}$ & $1-4$ & $>25$ \\
\hline
\end{tabular}

Table 2 Adopted specifications from IMSD guidelines for Check dams

Initially, the impact of each of these parameters was analysed using the AHP. Based on the importance as given in Table 1, the parameters were assigned values as shown in Table 3 .

\begin{tabular}{|c|c|c|c|c|}
\hline $\begin{array}{l}\text { Suitability } \\
\text { Factors }\end{array}$ & 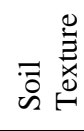 & $\frac{\ddot{\circ}}{\tilde{n}}$ & 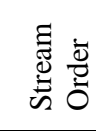 & 茑言 \\
\hline Soil Texture & 9 & 1.29 & 1.29 & 0.56 \\
\hline Slope & 7 & 1.00 & 1.00 & 1.40 \\
\hline Stream Order & 7 & 1.00 & 1.00 & 1.40 \\
\hline Curve Number & 5 & 0.71 & 0.71 & 1.00 \\
\hline Column Sum & 28 & 4.00 & 4.00 & 4.36 \\
\hline
\end{tabular}

(a) Comparison Matrix

\begin{tabular}{|c|c|c|c|c|c|}
\hline $\begin{array}{l}\text { Suitability } \\
\text { Factors }\end{array}$ & 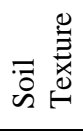 & $\frac{0}{0}$ & 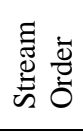 & 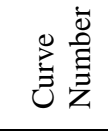 & $\begin{array}{l}\frac{\overrightarrow{0}}{000} \\
\frac{0}{3}\end{array}$ \\
\hline Soil Texture & 0.32 & 0.32 & 0.32 & 0.13 & 0.27 \\
\hline Slope & 0.25 & 0.25 & 0.25 & 0.32 & 0.27 \\
\hline Stream Order & 0.25 & 0.25 & 0.25 & 0.32 & 0.27 \\
\hline Curve Number & 0.18 & 0.18 & 0.18 & 0.23 & 0.19 \\
\hline
\end{tabular}

(b) Normalised Matrix

Table 3. Deriving relative weights of the suitability factors

It is found that the soil texture, stream order and slope have equal weightage as these are the main considerations in defining suitable site for check dam. The weightage calculation for each and every parameter considered in the analysis are given subsequently.

\subsection{Soil Texture Weightage Map}

Soil plays important role for holding the water at surface level. Hence the maximum weightage is assigned to soil layer. Further, among the classes, clayey is most favourable class, compared to the other type of soils because of its relative higher percentage of runoff potential than other soil types and lower percolation rate. So highest internal weightage is assigned to clay and lowest weightage is given to sandy soil as given in the Table 4 .

\begin{tabular}{|l|c|c|}
\hline Soil Texture & Clay & Loam \\
\hline Clay & 9 & 1.29 \\
\hline Loam & 7 & 1.00 \\
\hline Column Sum & 16 & 2.29 \\
\hline
\end{tabular}

(a)

Comparison matrix 


\begin{tabular}{|l|c|c|c|}
\hline Soil Texture & Clay & Loam & Weight \\
\hline Clay & 0.56 & 0.56 & 0.56 \\
\hline Loam & 0.44 & 0.44 & 0.44 \\
\hline
\end{tabular}

(b) Normalized matrix

Table 4. Deriving the relative weights of the soil texture parameter

The weightage map is generated by reclassifying the classes as shown in Figure 7. The areas with higher clay proportions is the best soil textural class compared to other soils because of its low infiltration and percolation rate it holds more water on the surface.

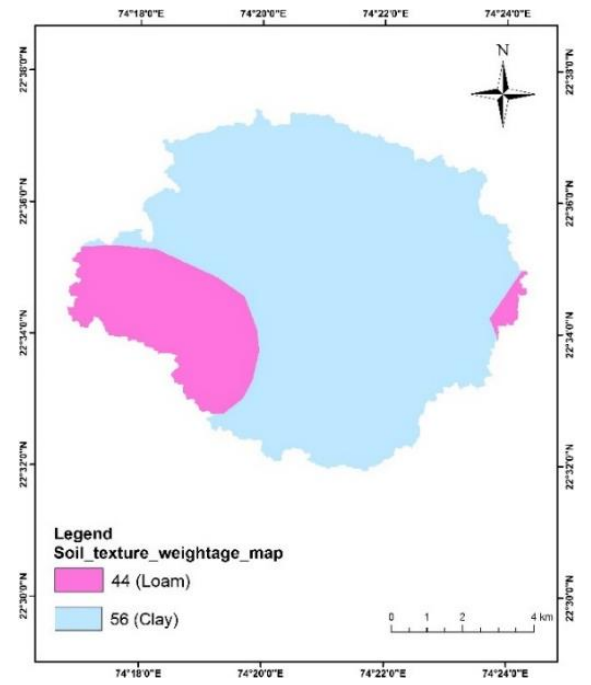

Figure 7. Soil Texture Weightage Map

\subsection{Slope weightage map}

Steep slopes generally serve to harvest runoff water. However, for check dam type of structure, moderate slopes are considered most suitable for check dam type of water harvesting and gentle slopes are considered least favourable. Based on the aforesaid facts, weightage is given in the decreasing order to the slope categories from very steep (>35\%), to nearly level $(0-1 \%)$ as shown in Table 5 . The study area has varying slope from nearly level to very steep sloping. Slope map has been generated from the ASTER DEM. Slope is one of the important factors determining the suitable site for water harvesting structure since the water flows from higher elevation to lower elevation following the steepest gradient. The slope $<15 \%$ is most suitable slope area for the construction of check dams. The reclassified slope percent map of the watershed based on the weightages assigned is shown in Figure 8.

\subsection{Stream Order Weightage Map}

The study area had the stream order from 1-4. Stream order map was generated through hydro-processing of DEM using spatial analyst tools of ArcGIS. The weights are given to each stream order based on the AHP technique as shown in Table 6. The stream order from 1-4 are suitable for check dams.

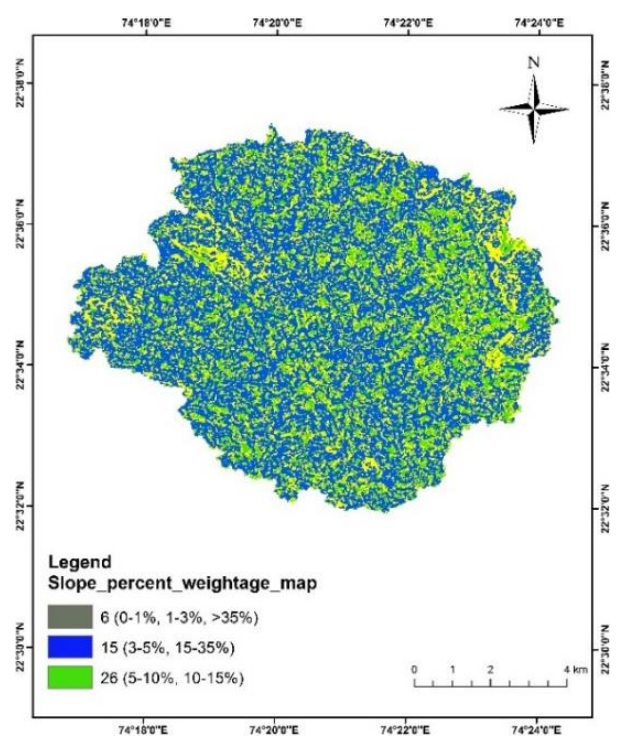

Figure 8. Slope percent weightage map

\begin{tabular}{|l|c|c|c|c|c|c|c|}
\hline Slope (\%) & $\begin{array}{c}\text { Nearly level } \\
(0-1 \%)\end{array}$ & $\begin{array}{c}\text { Very gentle } \\
(1-3 \%)\end{array}$ & $\begin{array}{c}\text { Gentle } \\
(3-5 \%)\end{array}$ & $\begin{array}{c}\text { Moderate Strong } \\
(5-10 \%)\end{array}$ & $\begin{array}{c}\text { Strong } \\
(10-15 \%)\end{array}$ & $\begin{array}{c}\text { Moderate Steep } \\
(15-35 \%)\end{array}$ & $\begin{array}{c}\text { Very steep } \\
(>35 \%)\end{array}$ \\
\hline Nearly level (0-1\%) & 2 & 1.00 & 0.40 & 0.22 & 0.22 & 0.40 & 1.00 \\
\hline Very gentle (1-3\%) & 2 & 1.00 & 0.40 & 0.22 & 0.22 & 0.40 & 1.00 \\
\hline Gentle (3-5\%) & 5 & 2.50 & 1.00 & 0.56 & 0.56 & 1.00 & 2.50 \\
\hline Moderate Strong (5-10\%) & 9 & 4.50 & 1.80 & 1.00 & 1.00 & 1.80 & 4.50 \\
\hline Strong (10-15\%) & 9 & 4.50 & 1.80 & 1.00 & 1.00 & 1.80 & 4.50 \\
\hline Moderate Steep (15-35\%) & 5 & 2.50 & 1.00 & 0.56 & 0.56 & 1.00 & 2.50 \\
\hline Very steep (>35\%) & 2 & 1.00 & 0.40 & 0.22 & 0.22 & 0.40 & 1.00 \\
\hline Column Sum & 34.00 & 17.00 & 6.80 & 3.78 & 3.78 & 6.80 & 17.00 \\
\hline
\end{tabular}

(a) Computation matrix for slope

\begin{tabular}{|c|c|c|c|c|c|c|c|c|}
\hline Slope $(\%)$ & $\begin{array}{c}\text { Nearly level } \\
(0-1 \%)\end{array}$ & $\begin{array}{c}\text { Very gentle } \\
(1-3 \%)\end{array}$ & $\begin{array}{l}\text { Gentle } \\
(3-5 \%)\end{array}$ & $\begin{array}{c}\text { Moderate Strong } \\
(5-10 \%)\end{array}$ & $\begin{array}{c}\text { Strong } \\
(10-15 \%)\end{array}$ & $\begin{array}{c}\text { Moderate Steep } \\
(15-35 \%)\end{array}$ & \begin{tabular}{|c|}
$\begin{array}{c}\text { Very steep } \\
(>35 \%)\end{array}$ \\
\end{tabular} & Weight \\
\hline Nearly level (0-1\%) & 0.06 & 0.06 & 0.06 & 0.06 & 0.06 & 0.06 & 0.06 & 0.06 \\
\hline Very gentle (1-3\%) & 0.06 & 0.06 & 0.06 & 0.06 & 0.06 & 0.06 & 0.06 & 0.06 \\
\hline Gentle $(3-5 \%)$ & 0.15 & 0.15 & 0.15 & 0.15 & 0.15 & 0.15 & 0.15 & 0.15 \\
\hline Moderate Strong (5-10\%) & 0.26 & 0.26 & 0.26 & 0.26 & 0.26 & 0.26 & 0.26 & 0.26 \\
\hline Strong $(10-15 \%)$ & 0.26 & 0.26 & 0.26 & 0.26 & 0.26 & 0.26 & 0.26 & 0.26 \\
\hline Moderate Steep (15-35\%) & 0.15 & 0.15 & 0.15 & 0.15 & 0.15 & 0.15 & 0.15 & 0.15 \\
\hline Very steep $(>35 \%)$ & 0.06 & 0.06 & 0.06 & 0.06 & 0.06 & 0.06 & 0.06 & 0.06 \\
\hline
\end{tabular}

(b) Normalised matrix of slope

Table 5. Deriving the relative weights of the slope parameter 


\begin{tabular}{|l|c|c|c|c|}
\hline Stream Order & $1^{\text {st }}$ Order & $2^{\text {nd }}$ Order & $3^{\text {rd }}$ Order & $4^{\text {th }}$ Order \\
\hline $1^{\text {st }}$ Order & 7 & 0.78 & 0.78 & 1.00 \\
\hline $2^{\text {nd }}$ Order & 9 & 1.00 & 1.00 & 0.78 \\
\hline $3^{\text {rd }}$ Order & 9 & 1.00 & 1.00 & 0.78 \\
\hline $4^{\text {th }}$ Order & 7 & 0.78 & 0.78 & 1.00 \\
\hline Column sum & 32 & 3.56 & 3.56 & 3.56 \\
\hline
\end{tabular}

(a) Computation matrix of stream order

\begin{tabular}{|l|c|c|c|c|c|}
\hline Stream Order & $1^{\text {st }}$ Order & $2^{\text {nd }}$ Order & $3^{\text {rd }}$ Order & $4^{\text {th }}$ Order & Weight \\
\hline 1st order & 0.22 & 0.22 & 0.22 & 0.28 & 0.23 \\
\hline 2nd order & 0.28 & 0.28 & 0.28 & 0.22 & 0.27 \\
\hline 3rd order & 0.28 & 0.28 & 0.28 & 0.22 & 0.27 \\
\hline 4th order & 0.22 & 0.22 & 0.22 & 0.28 & 0.23 \\
\hline
\end{tabular}

(b) Normalised matrix for stream order:

Table 6. Deriving the relative weights of the stream order factor

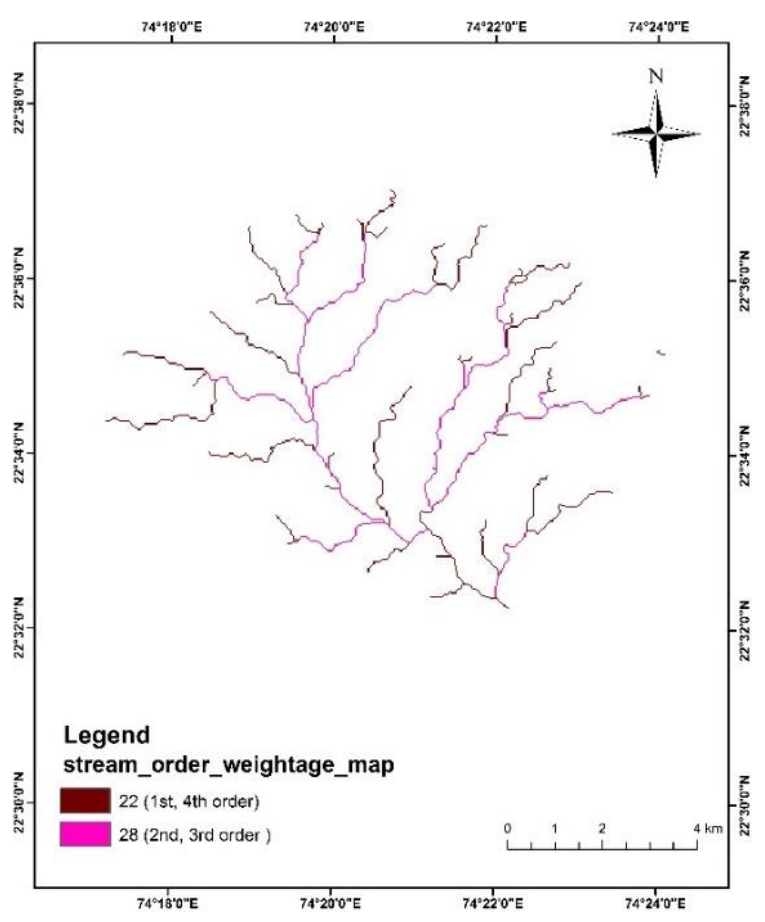

Figure 9. Stream order weightage map

\subsection{Curve Number Weightage Map}

Runoff is important factor in selecting the water harvesting structure. It can be represented from curve number and the low value indicates less runoff where as high value indicates more runoff. Curve number map represents the amount of runoff from a rainfall event at a particular area. The weightages are given to the different soils since curve number integrates soils and LULC of the area. The medium weights are most suitable site for water harvesting structure as shown in Table 7.

\begin{tabular}{|l|c|c|}
\hline Curve Number & Medium & High \\
\hline Medium & 5 & 1.25 \\
\hline High & 4 & 1.00 \\
\hline Column sum & 9 & 2.25 \\
\hline
\end{tabular}

(a) Computation of for Curve number

\begin{tabular}{|l|c|c|c|}
\hline $\begin{array}{l}\text { Normalised } \\
\text { matrix }\end{array}$ & Medium & \multicolumn{1}{l|}{ High } & Weight \\
\hline Medium & 0.56 & 0.56 & 0.56 \\
\hline High & 0.44 & 0.44 & 0.44 \\
\hline
\end{tabular}

(b) Normalised matrix for Curve number:

Table 7. Deriving the relative weights of the runoff factor

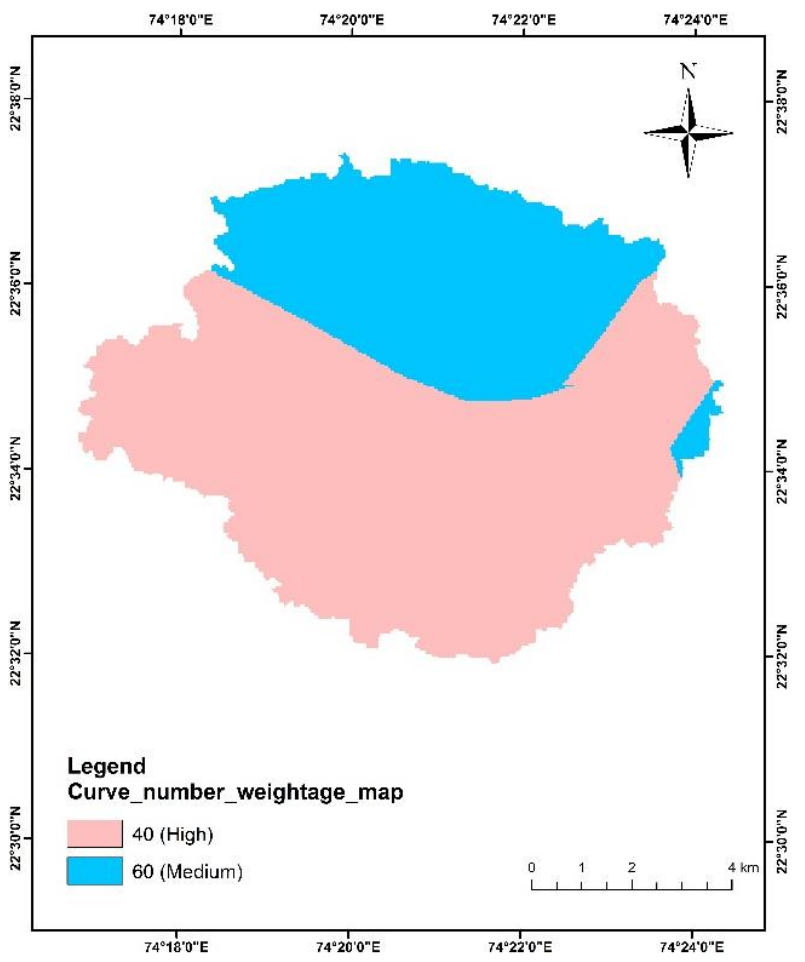

Figure 10. Curve number weightage map

\subsection{Suitable Site Map of Check Dam}

For decision making on suitable site for check dam, integration of all the thematic layers and weightage values, as a composite map is required. The map of suitable sites for check dam is generated by weighted overlay analysis of all four input layers, discussed above, in spatial analyst tools of the ArcGIS. The suitable sites are then categorised into three suitability categories (e.g. Less suitable, Suitable and Highly Suitable) The sites have overall score in the range of 150 -171 in the overall weighted map are assigned to the highly suitable category for construction of check dam. The final site suitability map for check dams in Hatni watershed is shown in Figure 11.

To understand the accuracy results obtained in the present study, an attempt was made to correlate the remote sensing derived (potential suitable sites) map and field based site suitability map for a small micro-watershed area. It was evident from proximity analysis that the check dams constructed in this watershed are mostly falling in most suitable sites identified using remote sensing approach. 


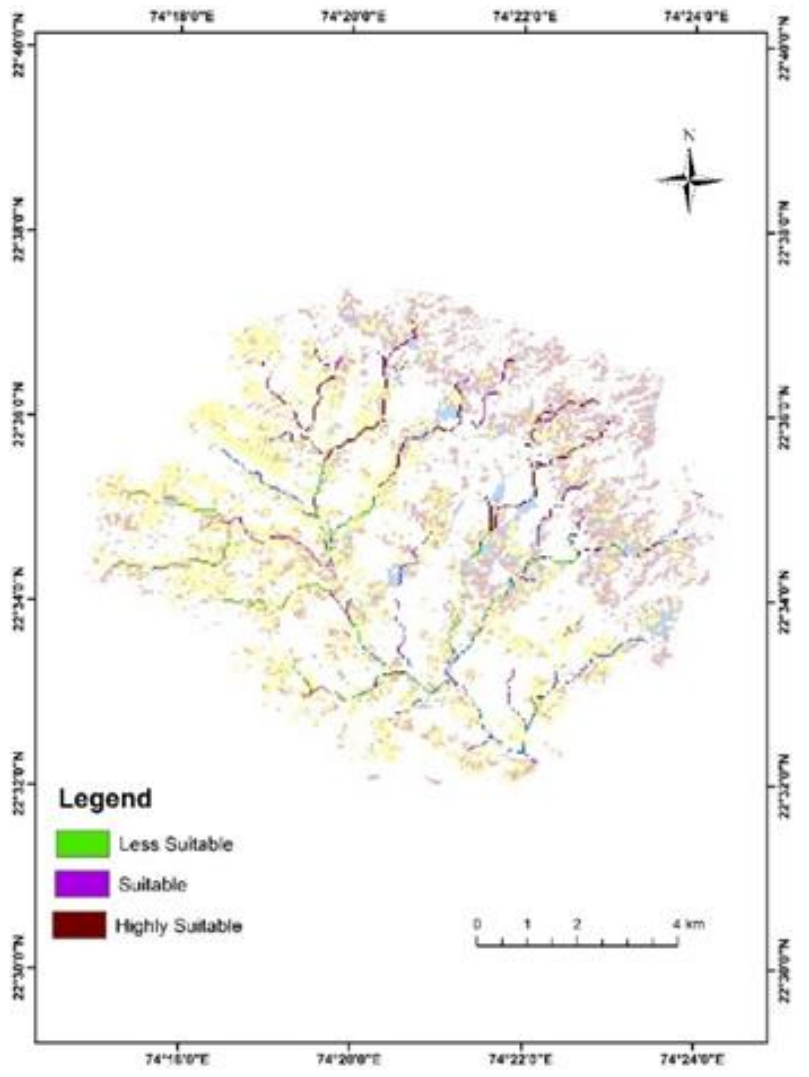

Figure 11. Potential site for Check dam

\subsection{Impact of Water Harvesting Structure on Land Use Land Cover}

As shown earlier that the existing check dam lies on the most suitable locations identified using AHP technique in GIS environment. Most of these structures are constructed in early 1990 's. Therefore, in the present study, as already two decades have passed since the construction of the water harvesting structures in the watershed, the impact of such structures on the vegetative surface has been analysed. For the analysis, the LULC map of before (1989) and after (2017) the construction of these structure were generated through using remote sensing datasets. The satellite data of same season in both the years were selected to avoid the seasonality effect. It was found that the water harvesting structure has positive impact on LULC of the study area. The vegetative surface has increased due to increased availability of water in proximity of these structures. The vegetation area in the study area is less in the year 1989 however, after construction of check dam the vegetation has increased around the command area of the check dam as shown in Figure 12.

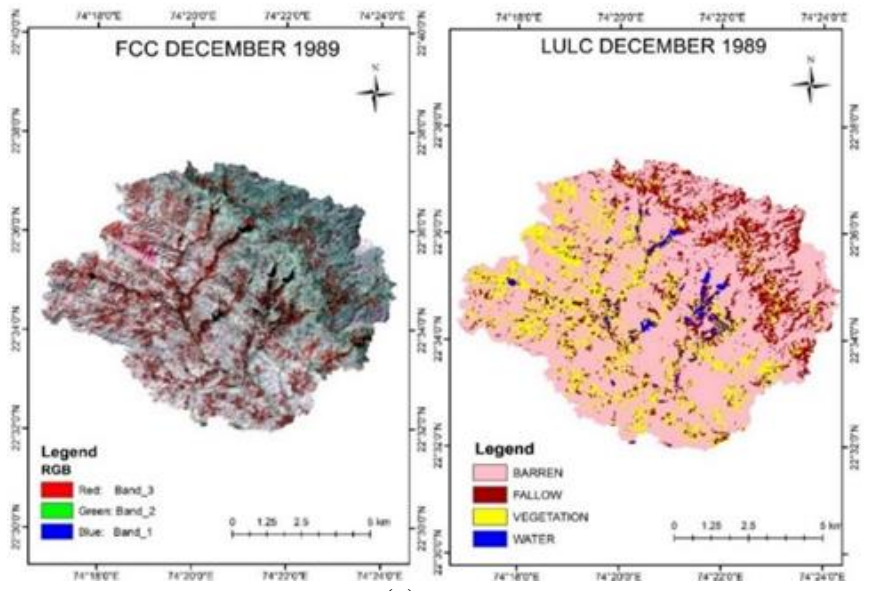

(a)

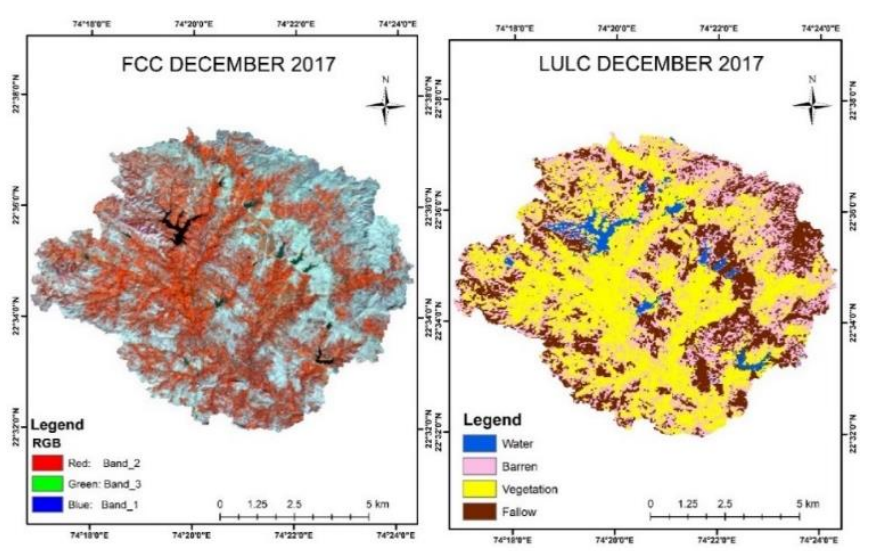

(b)

Figure 12 Maps showing FCC and LULC (a) 1989 and (b) 2017

\section{SUMMARY AND CONCLUSIONS}

In this study, implementation of AHP technique integrating with geospatial technology to find suitable sites for check dam construction was attempted successfully. Four factors including slope, soil texture, stream order, and curve number were selected as input for decision making and the weights for each factors were determined by AHP technique. The suitable sites for check dam were identified thorough weighted overlay analysis of the input factors. In this study, the results of suitable sites for check dam construction were verified with already constructed check dams in the watershed. As the water conservation practices in the watershed were initiated in early 1990's an attempt has been made to study the impact of such structures. The impact has been analysed in terms of change in vegetative coverage. It observed that there is a manifold increase in vegetative surface in and around the command of these structures. It may be concluded that AHP is most suitable approach for multi criteria decision making. There is a huge potential of geospatial technology in site suitability analysis.

\section{REFERENCES}

Abdulla Umar Naseef, T., \& Thomas, R. (2016). Identification of Suitable Sites for Water Harvesting Structures in Kecheri River Basin. Procedia Technology, 24, pp. 7-14. https://doi.org/10.1016/j.protcy.2016.05.003

Akinci, H., Özalp, A. Y., \& Turgut, B. (2013). Agricultural land 
use suitability analysis using GIS and AHP technique. Computers and Electronics in Agriculture, 97, pp. 71-82. https://doi.org/10.1016/j.compag.2013.07.006

FAO. 1977. "Guidelines for Watershed Management". In FAO Conservation Guide No.1, 293Rome: FAO.

Krois, J., \& Schulte, A. (2014). GIS-based multi-criteria evaluation to identify potential sites for soil and water conservation techniques in the Ronquillo watershed, northern Peru. Applied Geography, 51, pp. 131-142. https://doi.org/10.1016/j.apgeog.2014.04.006

Ramakrishnan, D., Durga Rao, K. H. V., \& Tiwari, K. C. (2008). Delineation of potential sites for water harvesting structures through remote sensing and GIS techniques: A case study of Kali watershed, Gujarat, India. Geocarto International, 23(2), $\quad$ pp. 95-108. https://doi.org/10.1080/10106040701417246

National Remote Sensing Agency (NRSC) 1995. Integrated Mission for Sustainable Development. Technical Guidelines, National Remote Sensing Agency, Balanagar, Hyderabad, India.

Sharma, A.K. and Thakur P. K. (2007). Quantitative assessment of sustainability of proposed watershed development plans for Kharod watershed, Western India. Journal of the Indian Society of Remote Sensing 35(3), pp. 231241

Saaty, T. L. (2008). Decision making with the analytic hierarchy process. International Journal of Services Sciences, 1(1), pp. 83. https://doi.org/10.1504/IJSSCI.2008.017590

SCS (Soil Conservation Service) (1972) SCS National Engineering Handbook, Section 4. Hydrology, Soil Conservation Service. US Department of Agriculture, Washington, DC.

Şener, Ş., Şener, E., Nas, B., \& Karagüzel, R. (2010). Combining AHP with GIS for landfill site selection: A case study in the Lake Beyşehir catchment area (Konya, Turkey). Waste Manag. 30(11): pp. 2037-46. doi: 10.1016/j.wasman.2010.05.024.

Talati, J., Kumar, M. D. and Ravindranath, R. (2005). Local and Sub-Basin Level Impacts of Local Watershed Development Projects: Hydrological and Socio-economic Analysis of Two Sub-Basins of Narmada, Water Policy Research Highlight 15, IWMI-Tata Water Policy Research Program, Anand, Gujarat, India 